\title{
Selective template removal by thermal depolymerization to obtain mesostructured molybdenum oxycarbide
}

\author{
Martin Schieder, ${ }^{[\mathrm{a}]}$ Thomas Lunkenbein, ${ }^{[\mathrm{b}]}$ Carina Bojer, ${ }^{[\mathrm{a}]}$ Martin Dulle, ${ }^{[\mathrm{c}]}$ Julia vom Stein, ${ }^{[\mathrm{d}]}$ \\ Gudrun Auffermann, ${ }^{[\mathrm{e}]}$ Tina Löbling, ${ }^{[\mathrm{f}]}$ Judith Schöbel, ${ }^{[\mathrm{f}]}$ Holger Schmalz, ${ }^{[\mathrm{f}]}$ and Josef Breu* ${ }^{[\mathrm{a}]}$
}

\author{
Dedicated to Prof. Dr. J. Grin on the Occasion of his $60^{\text {th }}$ birthday.
}

Keywords: organic-inorganic hybrid composites; template synthesis; template removal by depolymerization; non-woven network; calcination

\begin{abstract}
The carbon content of mesostructured organic-inorganic hybrid material of a cylindrical block copolymer template of poly(2vinylpyridine)-block-poly(allyl methacrylate) (P2VP-b-PAMA) and ammonium paramolybdate (APM) could be reduced by thermal depolymerization. By calcination in vacuum at $320^{\circ} \mathrm{C}$ the PAMA core can be completely removed while the remaining P2VP brush preserves the mesostructure.
\end{abstract}

The P2VP-APM composite can then be carburized in-situ to $\mathrm{MoO}_{\mathrm{x}} \mathrm{C}_{\mathrm{y}}$ in a second pyrolysis step without any additional carbon source but P2VP. The molybdenum oxycarbide nanotubes obtained, form hierarchically porous non-woven structures which were tested as catalyst in the decomposition of $\mathrm{NH}_{3}$. They proved to be catalytically active at temperatures above $450{ }^{\circ} \mathrm{C}$. The activation energy was estimated from an Arrhenius Plot to be $127 \mathrm{~kJ} \mathrm{~mol}^{-1}$.

\author{
* $\quad$ Prof. Dr. J. Breu \\ Fax: +49-921-55-2788 \\ E-Mail: josef.breu@uni-bayreuth.de \\ [a] Lehrstuhl für Anorganische Chemie I \\ Universität Bayreuth \\ Universitätsstr. 30 \\ 95440 Bayreuth, Germany \\ [b] Fritz-Haber Institut der Max-Planck Gesellschaft \\ Abteilung Anorganische Chemie \\ Faradayweg 4-6 \\ 14195 Berlin, Germany \\ [c] Lehrstuhl für Physikalische Chemie I \\ Universität Bayreuth \\ Universitätsstr. 30 \\ 95440 Bayreuth, Germany \\ [d] Max-Planck Institut für Kohlenforschung \\ Abteilung Heterogene Katalyse \\ Kaiser-Wilhelm-Platz 1 \\ 45470 Mülheim a.d. Ruhr, Germany \\ [e] Max-Planck-Institut für Chemische Physik fester Stoffe \\ Nöthnitzer Straße 40 \\ 01187 Dresden, Germany \\ [f] Lehrstuhl für Makromolekulare Chemie II \\ Universität Bayreuth \\ Universitätsstr. 30 \\ 95440 Bayreuth, Germany
}

Supporting information for this article is available on the WWW under http://dx.doi.org/10.1002/zaac.201000xxx or from the author.

\section{Introduction}

Ammonia is one candidate currently explored as hydrogen carrier molecule to replace fossil fuels in mobile applications. ${ }^{[1]}$ The energy stored is recovered by decomposition which requires highly active heterogeneous catalysts. Up to now, this field is dominated by rare and expensive noble metals. ${ }^{[2]}$ In a pioneering work, Levy and Boudart showed that the catalytic activity of group 6 transition metal carbides is similar or even surpassing those of noble metals. ${ }^{[3]}$ Traditional carburization methods are based on high temperature reactions of metals with carbon. ${ }^{[4]}$ However, these approaches result in coarse grained carbides with low accessible surface area. For high surface area temperature programmed reduction of transition metal oxides to form carbides has been applied. ${ }^{[5]}$

The synthesis of hierarchically porous carbides that would promote mass transport, requires structuring of oxidic inorganic precursor on the mesoscale applying appropriate structure directing agents. ${ }^{[6]}$ We have previously shown that organic templates applied for mesostructuring heteropolyacids can concomitantly be used as carbon source to drive the carburization of oxidic precursors. ${ }^{[7]}$ With poly(butadiene)-block-poly(2-vinylpyridine) (PB-b-P2VP) used as template, the ratio of metal cations and the carbon content could, however, not be adjusted post formation of the hybrid material in order to meet the stoichiometry required for a quantitative carbide formation. The walls of the mesostructured transition metal carbide obtained were consequently found to be coated by a thin layer of carbon formed by pyrolysis from the excess of carbon. The removal of the residual carbon inside the pores proved impossible leading to partial blockage of the inner surface area. ${ }^{[8]}$ To obtain carbon-free mesostructured transition metal carbides the carbon content needs to be reduced prior to the carburization step without loss of the mesostructure.

It was shown for SBA-15, that despite stepwise removal of a poly(ethylene oxide)-block-poly(propylene oxide)block-poly (ethylene oxide) (Pluronic P123) template by acidic ether cleavage followed by solvent leaching of the detached block, the mesostructure is preserved. ${ }^{[9]}$

Here, we explore thermal depolymerization of an appropriate template to reduce the carbon content of the hybrid material prior to carburization. Ammonium paramolybdate (APM: $\left.\left(\mathrm{NH}_{4}\right)_{6} \mathrm{Mo}_{7} \mathrm{O}_{24}\right)$ was used as molyb- 
denum precursor together with rigid, tailor-made poly(2vinylpyridine)-block-poly(allyl methacrylate) P2VP-bPAMA diblock copolymer cylindrical brushes as structuredirecting agent. Coulomb interactions between the protonated P2VP brush $^{[10]}$ and the isopolyoxomolybdate lead to robust hybrid formation (Scheme 1D). The PAMA core of this diblock copolymer allows on one hand for crosslinking of the formed hexagonal microphase (Scheme 1B) to obtain rigid nanowires to be applied as template (Scheme 1C). On the other hand, the low depolymerization temperature later allows for facile removal of the core of the hybrid materials, whereas the P2VP brush stabilizes the mesostructure (Scheme 1E). During subsequent carburization, the P2VP brush then serves as carbon source to obtain mesostructured carbide (Scheme 1F).

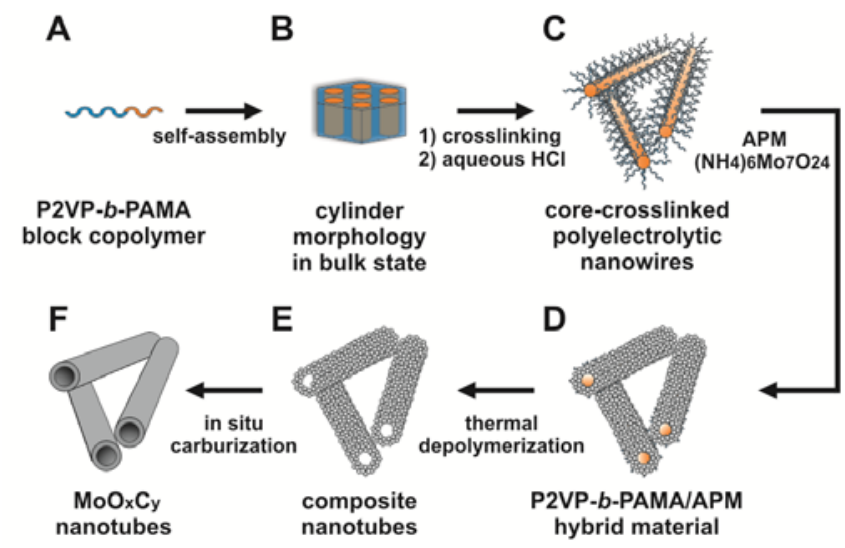

Scheme 1. Schematic route to molybdenum oxycarbide nanotubes: self-assembly of P2VP-b-PAMA diblock copolymer (A) and crosslinking of the hexagonally packed PAMA cylinders in the bulk state (B), dissolution of rigid cylindrical template in aqueous $\mathrm{HCl}$ (C), addition of APM precursor for hybrid formation (D), thermal depolymerization of PAMA core (E) and carburization of P2VP brush to $\mathrm{MoO}_{\mathrm{x}} \mathrm{C}_{\mathrm{y}}$ nanotubes $(\mathrm{F})$.

\section{Results and Discussion}

\section{P2VP-b-PAMA/APM hybrid nanowires}

SAXS measurements of the self-assembled and crosslinked P2VP-b-PAMA diblock copolymer film (Scheme 1B, Figure SI1) showed the formation of a hexagonally ordered microstructure, which corresponds to cylindrical PAMA domains embedded in a P2VP matrix. The radius of these hexagonally ordered domains was calculated to be $110 \mathrm{~nm}$. The diameter of the cylindrical PAMA domains was calculated to be $27.4 \mathrm{~nm}$.

The crosslinked polymer film can be dispersed into cylindrical nanobrushes by $\mathrm{HCl}$. TEM images of the P2VP$b$-PAMA nanobrushes confirmed the formation of rigid cylinder micelles (Figure SI2). The diameter of the PAMA core is $30 \mathrm{~nm}$, which is in line with the value from SAXS measurements of the hexagonal bulk film. The overall diameter of the cylinders including the charged P2VP-brush is estimated to be $85 \mathrm{~nm}$.

Decomposition temperatures of the individual blocks were determined by TG-MS of the hexagonal bulk films (Figure 1). The PAMA block decomposed at $280{ }^{\circ} \mathrm{C}$, the corresponding MS signal indicates the release of a propenefragment $(\mathrm{m} / \mathrm{z}=41) \cdot{ }^{[11]}$ The degradation of the P2VP brush commenced at significantly higher temperatures $\left(>395^{\circ} \mathrm{C}\right)$ as indicated by a MS signal of pyridine $(\mathrm{m} / \mathrm{z}=79) \cdot{ }^{[12]}$ The small peak of the propene fragment observed at higher decomposition temperature $\left(395{ }^{\circ} \mathrm{C}\right)$ might either be attributed to a delayed release of PAMA due to a coating of P2VP at the core-shell transition zone or to a decomposition of the pyridine ring to a fragment of $\mathrm{m} / \mathrm{z}=41$ as reported in the literature. ${ }^{[12]}$ Since the cumulative mass loss $(25 \%)$ up to $320^{\circ} \mathrm{C}$ corresponds with the weight content of PAMA in the block copolymer the latter explanation appears more likely.

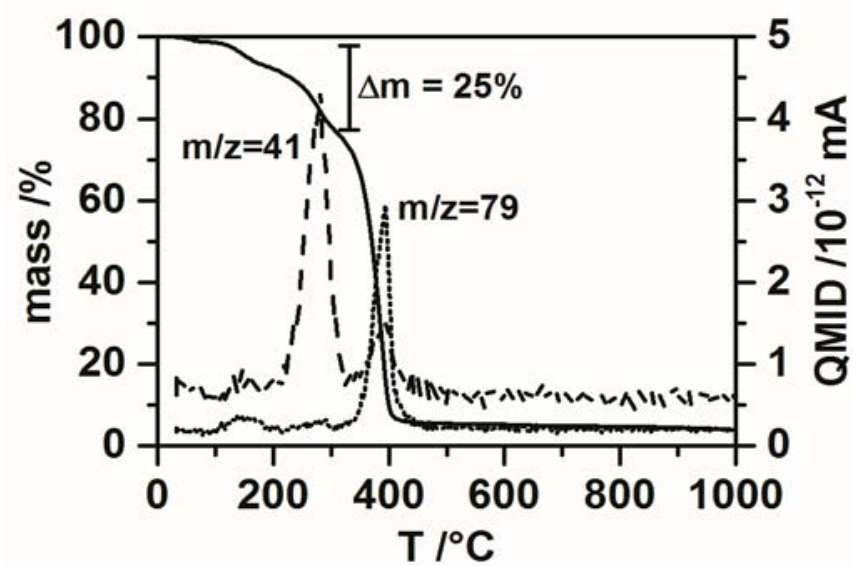

Figure 1. TG-MS measurement of P2VP-b-PAMA block copolymer (solid line) and quasi multiple ion detection (QMID) signals of propene fragment of PAMA $(\mathrm{m} / \mathrm{z}=41$, dashed line) and pyridine $(\mathrm{m} / \mathrm{z}=79$, dotted line).

The hybrid formed between positively charged P2VP- $b$ PAMA nanobrushes and APM was amorphous (Scheme 1D, Figure 2A). No phase segregation of the crystalline inorganic precursor was observed suggesting that the paramolybdate was homogenously incorporated, most likely as molecular moiety into the P2VP brush.

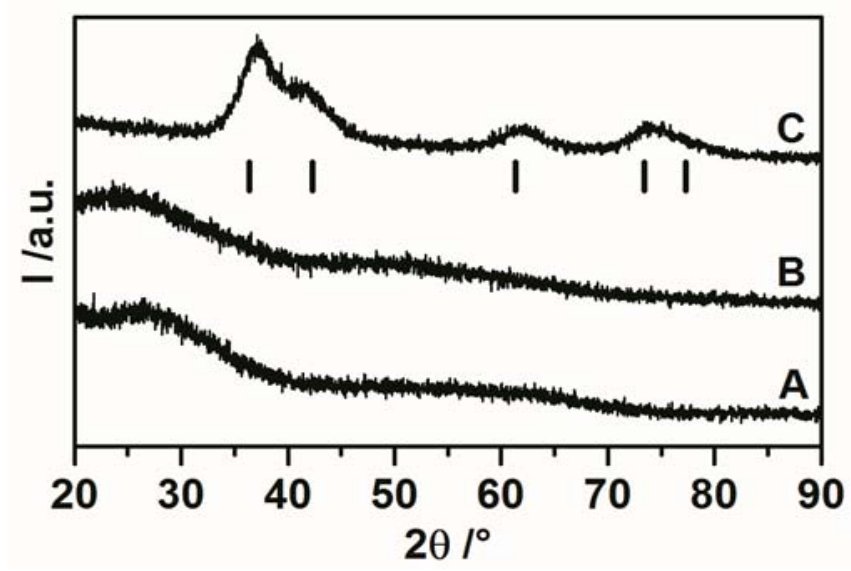

Figure 2. XRD measurements of P2VP-b-PAMA/APM hybrid material (A), composite after thermal depolymerization in vacuum (B) and $\mathrm{MoO}_{\mathrm{x}} \mathrm{C}_{\mathrm{y}}$ nanotubes after carburization in argon atmosphere (C). The row of tick marks indicates the peak positions of cubic $\mathrm{MoC}_{1-\mathrm{x}}$ (ICSD 77157).

SEM images of the P2VP-b-PAMA/APM hybrid material exhibited well dispersed singular hybrid cylinders that upon drying agglomerated into a spaghetti-like non-woven network (Figure 3, SEM Hybrid). The surface of the hybrid cylinders is rather rough due to incorporation of paramolybdate clusters. TEM measurements of the P2VP- 

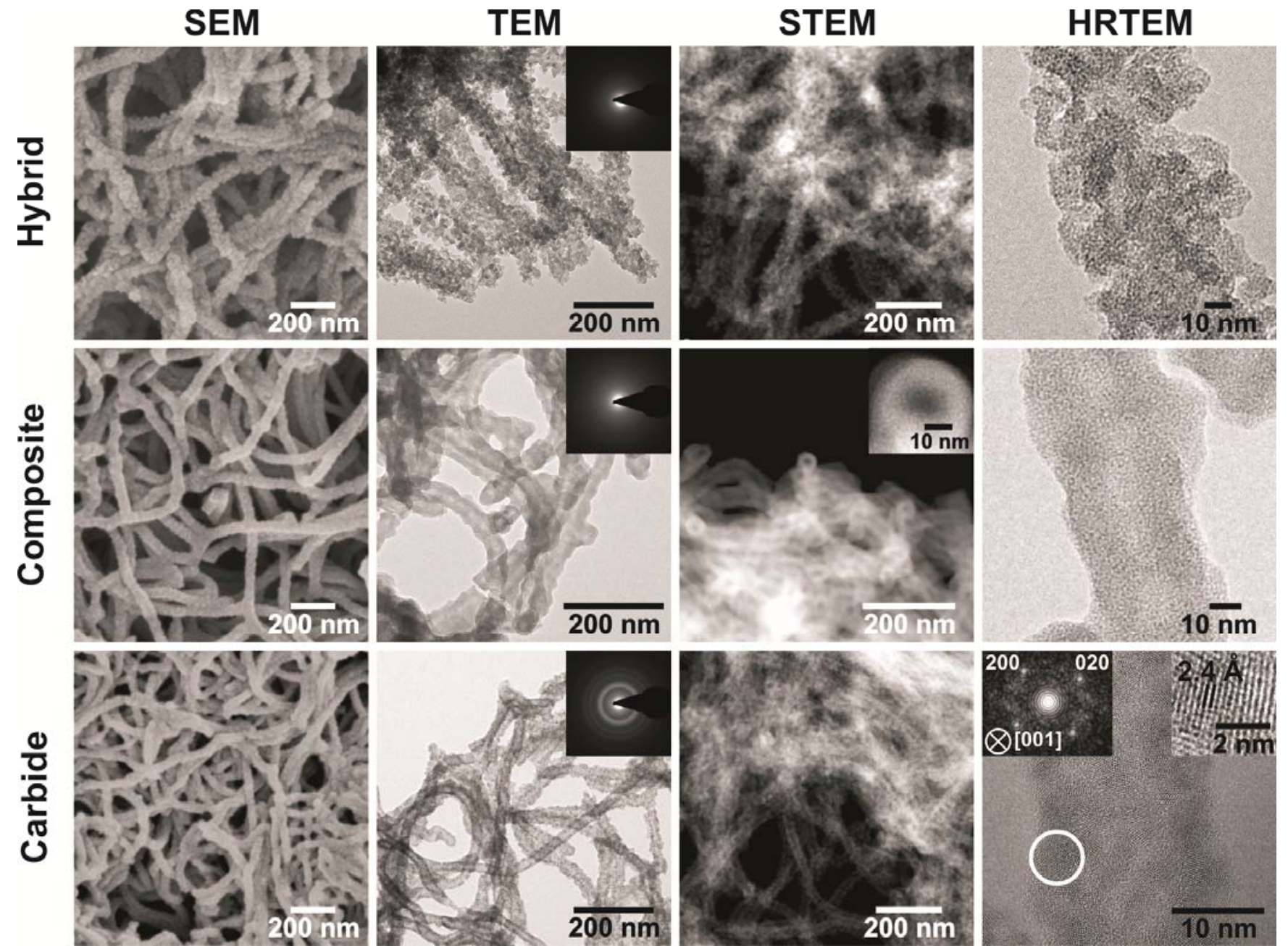

Figure 3. SEM, TEM, STEM and HRTEM images of P2VP-b-PAMA/APM hybrid material, composite after thermal depolymerization in vacuum and $\mathrm{MoO}_{\mathrm{x}} \mathrm{C}_{\mathrm{y}}$ nanotubes after carburization in argon atmosphere (inset in TEM column: SAED). The left inset in the HRTEM of the carbide denotes a power spectrum of the marked region of interest viewed along [001] of cubic $\mathrm{MoO}_{\mathrm{x}} \mathrm{C}_{\mathrm{y}}$.

b-PAMA/APM hybrid cylinders confirmed the homogeneous incorporation of the paramolybdate into the P2VP brush (Figure 3, TEM Hybrid). The diameter of the cylinders derived from TEM measurements is $49 \mathrm{~nm} \pm 7$ $\mathrm{nm}$. The relatively large error may be attributed to the surface roughness. The diffuse pattern of the selected area electron diffraction (SAED) measurement indicated an amorphous material and further verified the homogeneous incorporation of paramolybdate in the P2VP brush (inset, Figure 3, TEM Hybrid). This observation is also confirmed by a homogenous contrast in the high angel annular dark field scanning TEM (HAADF-STEM) images (Figure 3, STEM Hybrid). In HAADF-STEM the contrast is due to Rutherford scattering being proportional to $Z^{2}$. HRTEM images of the P2VP-b-PAMA/APM hybrid material again underline the high surface roughness of the hybrid cylinders with a caterpillar-like shape (Figure 3, HRTEM Hybrid).

$\mathrm{N}_{2}$-physisorption measurements of the P2VP- $b$-PAMA /APM hybrid material exhibited a Type II isotherm with a slight hysteresis indicating a mesoporous material with interparticular pores (Figure 4A). The specific surface area was calculated to be $77 \mathrm{~m}^{2} \mathrm{~g}^{-1}$ by the Brunauer-EmmettTeller (BET) equation. This value appears rather high and can be designated to the non-woven network and the high surface roughness of the hybrid cylinders as observed in electron microscope images. BJH (Barret-Joyner-Halenda) pore-size distribution showed a broad distribution of pores in line with this view (inset Figure 4A).

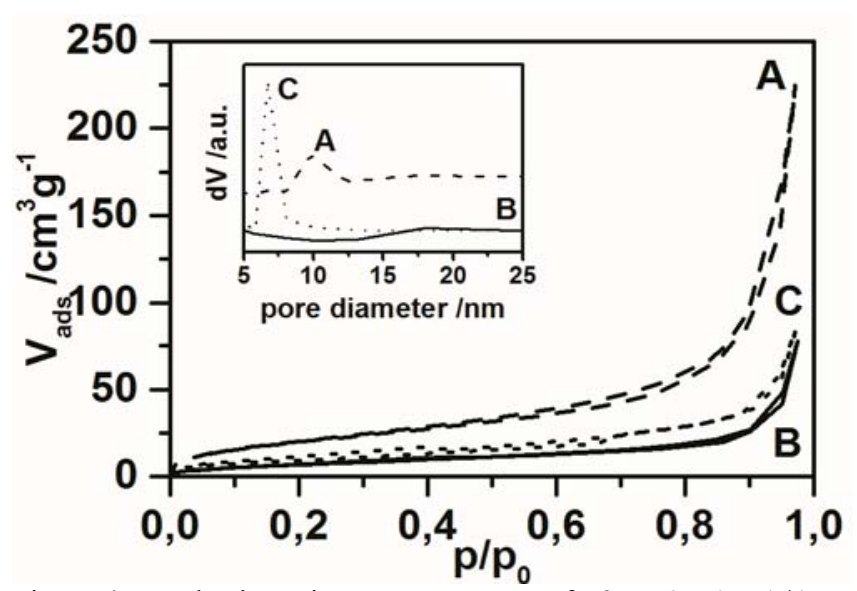

Figure 4. $\mathrm{N}_{2}$-physisorption measurements of P2VP-b-PAMA/APM hybrid material (dashed line, A), composite after thermal depolymerization in vacuum (solid line, $\mathrm{B}$ ) and $\mathrm{MoO}_{\mathrm{x}} \mathrm{C}_{\mathrm{y}}$ nanotubes after carburization in argon atmosphere (dotted line, C). (Inset: Corresponding BJH-pore size distribution). 
Table 1. Structural details of P2VP-b-PAMA/APM hybrid material, of composite after thermal depolymerization in vacuum and $\mathrm{MoO}_{\mathrm{x}} \mathrm{C}_{\mathrm{y}}$ nanotubes after carburization in argon atmosphere.

\begin{tabular}{lccc}
\hline & $\begin{array}{c}\text { P2VP- } b- \\
\text { PAMA/APM } \\
\text { hybrid } \\
\text { material }\end{array}$ & $\begin{array}{c}\text { Argon } \\
\text { calcined } \\
\text { composite }\end{array}$ & $\begin{array}{c}\mathrm{MoO}_{\mathrm{x}} \mathrm{C}_{\mathrm{y}} \\
\text { nanotubes }\end{array}$ \\
\hline $\begin{array}{l}\text { Diameter } \\
\text { core } / \mathrm{nm}^{\mathrm{a}}\end{array}$ & - & $13 \pm 1$ & $11 \pm 1$ \\
$\begin{array}{l}\text { Diameter } \\
\text { brush } / \mathrm{nm}^{\mathrm{a}}\end{array}$ & $49 \pm 7$ & $40 \pm 5$ & $25 \pm 3$ \\
$\mathrm{BET} \mathrm{surface}$ & 77 & 27 & 36 \\
$\begin{array}{l}\text { area } / \mathrm{m}^{2} \mathrm{~g}^{-1} \\
\mathrm{C} / \mathrm{H} / \mathrm{N} / \mathrm{O}\end{array}$ & $39.3 / 4.9 /$ & $28.8 / 2.5 /$ & $26.8 / 0.3 /$ \\
content $/ \mathrm{wt} \%$ & $3.2 / 21.6$ & $4.9 / 21.0$ & $0.9 / 4.3$ \\
Crystallinity & $\begin{array}{l}\text { amorphous } \\
\text { a }\end{array}$ & amorphous & nanocrystalline \\
${ }^{\text {From TEM analysis }}$ & & \\
\hline
\end{tabular}

The carbon content of the P2VP-b-PAMA/APM hybrid cylinders was determined to be $39.3 \%$ by elemental analysis (Table 1).

\section{Removal of PAMA-core from P2VP-b-PAMA/APM hybrid material}

As discussed above, TG-MS of the P2VP- $b$-PAMA diblock copolymer cylinders (Figure 1) suggests that the PAMA block may selectively be depolymerized at $320{ }^{\circ} \mathrm{C}$. TG-MS of the hybrid material in helium atmosphere (Figure SI3) confirmed that the depolymerization temperature is not significantly affected by the presence of paramolybdate in the P2VP brush. Therefore the PAMA core was removed quantitatively and selectively by heating the hybrid material at $2 \mathrm{~h}$ in vacuum. By this depolymerization, the carbon content could indeed be reduced from $39.3 \mathrm{wt} \%$ to $28.8 \mathrm{wt} \%$ (Table 1). The nitrogen content increased during calcination by $53 \%$ to $4.9 \mathrm{wt} \%$, which is due to the removal of the nitrogen free PAMA block. The oxygen content decreased slightly by $3 \%$ to $21.0 \mathrm{wt} \%$.

XRD measurements of the hybrid material after calcination in vacuum showed no changes in the amorphous character of the resulting composite material (Figure 2B).

Additional SEM images revealed the intactness of the nonwoven network (Figure 3, SEM Composite), while the surface roughness decreased. It is not clear at this point whether the stability of the mesostructure is solely assured by P2VP chains or, as would be expected at a temperature of $320{ }^{\circ} \mathrm{C}$, whether by condensation of the hydroxyl groups of adjacent paramolybdate moieties a stable inorganic scaffold started to be formed. Condensation would be supported by the slight decrease of the oxygen content observed. An increased contrast between the core and the shell of the composite cylinders after vacuum calcination revealed a tubular character as shown in the TEM images (Figure 3, TEM Composite). The fact that the tubes did not collapse to cylinders during removal of the PAMA block might indicate that indeed an inorganic scaffold is formed during the depolymerization at $320{ }^{\circ} \mathrm{C}$. The overall diameter of the cylinders decreased by $18 \%$ to $40 \mathrm{~nm} \pm 5 \mathrm{~nm}$ (Table 1) due to smoothening of the surface roughness. The inner diameter of the tube is $13 \mathrm{~nm} \pm 1 \mathrm{~nm}$. The SAED pattern (inset, Figure 3, TEM Composite) of the material was still diffuse and corroborated the amorphous state observed in the XRD measurements (Figure 2B). STEM images of the composite also showed a clear contrast between the walls and the empty center of the cylinders indicating the formation of hollow tubes (Figure 3, STEM Composite). The inset moreover shows pore caps with a diameter of $14 \mathrm{~nm}$. HRTEM measurements of the composite (Figure 3, HRTEM Composite) confirmed the decrease of surface roughness as observed in SEM images. Additionally, the amorphous state and the homogeneous dispersion of the molybdenum oxide were still evident.

Calcination of the P2VP- $b$-PAMA/APM hybrid material in vacuum led to a decrease of the specific surface area by $65 \%$ to $27 \mathrm{~m}^{2} \mathrm{~g}^{-1}$, which can be attributed to the aforementioned decrease of surface roughness (Figure 4B). Additionally, sintering and densification of the tube walls might also contribute to the drop of surface area. Somewhat in contrast to the STEM images, BJH-pore-size distribution of the composite (inset, Figure 4B) showed no maximum. This would suggest that the inner surface of the tubes is not accessible. This in turn may be attributed to the closed endcaps and a non-porous nature of the walls.

\section{In situ carburization of the molybdenum oxide walls}

TG-MS of the hybrid material (Figure SI3) suggests that pyrolysis of the P2VP block sets in at around $395{ }^{\circ} \mathrm{C}$. Most likely due to the catalytic activity of molybdenum in its neighborhood, the pyridine moiety no longer is released unfragmented as observed for the pristine polymer template. Rather complete fragmentation to propene $(\mathrm{m} / \mathrm{z}=41)$ is observed.

According to the literature ${ }^{[7]}$ carburization of the molybdenum walls was achieved in argon atmosphere at $700{ }^{\circ} \mathrm{C}$ for $2 \mathrm{~h}$. No additional carbon source was needed. The carbon content of the P2VP brush remaining in the composite was fully sufficient. XRD measurements after carburization showed broad reflections at $36^{\circ}, 42^{\circ}, 61^{\circ}, 73^{\circ}$ and $77^{\circ} 2 \theta$ (Figure 2C) that can be indexed with a facecentered cubic cell of $\mathrm{MoC}_{1-\mathrm{x}}$ (ICSD 77157) or molybdenum oxycarbide $\mathrm{MoO}_{\mathrm{x}} \mathrm{C}_{\mathrm{y}}$. The carbon content decreased only slightly by $7 \%$ to $26.8 \mathrm{wt} \%$ during the carburization step. The residual carbon is mostly converted to molybdenum carbide (Table 1). Nitrogen was almost completely removed in this step and its content decreased by $82 \%$ to $0.9 \mathrm{wt} \%$. The oxygen content decreased by $80 \%$ from $21.0 \mathrm{wt} \%$ to $4.3 \mathrm{wt} \%$ during carburization. The presence of this low but significant amount of oxygen suggests the formation of a molybdenum oxycarbide species rather than a pure molybdenum carbide.

SEM images after carburization displayed the preservation of the non-woven structure (Figure 3, SEM Carbide). No obvious changes in surface roughness upon carburization could be observed. The preservation of the tubular character after carburization was confirmed by TEM images (Figure 3, TEM Carbide). The average diameter of the tubes decreased by $38 \%$ to $25 \mathrm{~nm}$. This fact can be explained by further densification of the walls during carburization. The inner diameter decreased only slightly to $11 \mathrm{~nm} \pm 1 \mathrm{~nm}$. The powder rings observed in SAED furthermore affirm the formation of a nanocrystalline material (inset, Figure 3 , TEM Carbide). The decrease of the wall-thickness is also approved by STEM images (Figure 3, STEM Carbide). HRTEM images underline the tubular character with molybdenum oxycarbide nanocrystals in the walls (Figure 3, HRTEM Carbide). The spacing of $2.4 \AA$ seen in the right inset corresponds to the (111) plane of $\mathrm{MoO}_{\mathrm{x}} \mathrm{C}_{\mathrm{y}}$. The power spectrum viewed along the [001] direction (left inset) as well shows reflections that can be related to cubic $\mathrm{MoC}_{1-\mathrm{x}}$ or 
$\mathrm{MoO}_{\mathrm{x}} \mathrm{C}_{\mathrm{y}}$. SAED indexing of the marked region also verified the formation of $\mathrm{MoC}_{1-\mathrm{x}}$ or $\mathrm{MoO}_{\mathrm{x}} \mathrm{C}_{\mathrm{y}}$ (Figure SI 4).

The shape of the adsorption isotherm of the molybdenum oxycarbide nanotubes in $\mathrm{N}_{2}$ physisorption measurements is similar to the isotherm of the composite (Figure 4C). The specific surface area, however, increased by $33 \%$ to $36 \mathrm{~m}^{2} \mathrm{~g}$ 1 . This increase in surface area most likely can be attributed to gaining access to the inner pore walls during carburization. BJH yields a maximum at $7 \mathrm{~nm}$ (inset, Figure 4C), which is significantly smaller than the inner diameter seen in TEM micrographs (Figure 3, TEM Carbide). This offset of the two methods might be due to constricted end-caps of the open tubes.

Additionally, the hierarchically porous molybdenum oxycarbide non-wovens were tested as catalyst in the decomposition of $\mathrm{NH}_{3}$. As shown in Figure 5, the molybdenum oxycarbide nanotubes are catalytically active at temperatures above $450{ }^{\circ} \mathrm{C}$. The activation energy was estimated from an Arrhenius Plot (inset, Figure 5) to be $127 \mathrm{~kJ} \mathrm{~mol}^{-1}$. This value is $20 \%$ lower than previously reported results for molybdenum oxycarbide $\left(156 \mathrm{~kJ} \mathrm{~mol}^{-}\right.$ $\left.{ }^{1}\right) .{ }^{[7]}$ In addition, the oxygen content in the $\mathrm{MoO}_{\mathrm{x}} \mathrm{C}_{\mathrm{y}}$ nanotubes is reduced by $65 \%$ compared to our previous report. ${ }^{[7]}$ Thus it seems likely that the lower oxygen content of the molybdenum oxycarbide nanotubes might enhance the catalytic activity. However, the activation energy of the benchmark system of pure hexagonal molybdenum carbide $\left(89 \mathrm{~kJ} \mathrm{~mol}^{-1}\right)$ is not reached. ${ }^{[14]}$

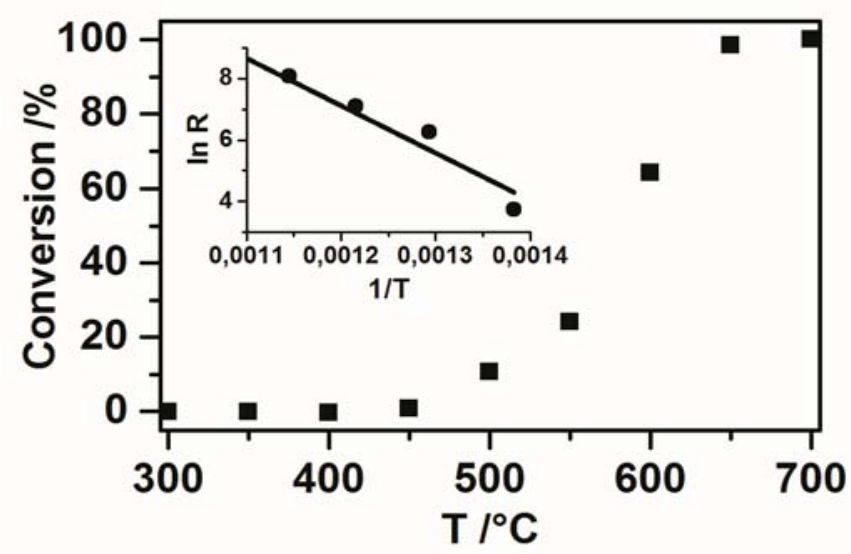

Figure 5. Catalytic decomposition of $\mathrm{NH}_{3}$ over $\mathrm{MoO}_{\mathrm{x}} \mathrm{C}_{\mathrm{y}}$ nanotubes from 300 to $700{ }^{\circ} \mathrm{C}$. (Inset: Arrhenius Plot obtained from decomposition of $\mathrm{NH}_{3}$ over $\mathrm{MoO}_{\mathrm{x}} \mathrm{C}_{\mathrm{y}}$ ).

\section{Conclusions}

Applying cationic, cylindrical P2VP-b-PAMA nanobrushes as a structure directing agent allows to reduce the carbon content of hybrid materials initially formed to be reduced by thermal decomposition of the PAMA block. The depolymerization step is well separated from the pyrolysis of the P2VP brush. The P2VP preserves the mesostructure despite removal of the core and at the same time it may serve as carbon source for carburization of the mesostructured oxidic transition metal precursor.

\section{Experimental Section}

Synthesis of poly(2-vinylpyridine)-block-poly(allylmethacrylate)
The diblock copolymer was synthesized via sequential living anionic polymerization in THF. Size exclusion chromatography (eluent THF) was used to determine the number-average molecular weight of the P2VP block and the polydispersity index (PDI) of the diblock copolymer. The overall number-average molecular weight of the P2VP-b-PAMA diblock copolymer was determined by ${ }^{1} \mathrm{H}-$ NMR to $\mathrm{M}_{\mathrm{n}}=74 \mathrm{~kg} \mathrm{~mol}^{-1}(\mathrm{PDI}=1.10)$ with a PAMA content of $25 \mathrm{wt} \%$. This composition was chosen to obtain a cylindrical microstructure in the bulk state with hexagonally packed PAMA cylinders in a P2VP matrix. Futher details on the synthesis and characterization of the P2VP-b-PAMA diblock copolymer is provided in the Supporting Information.

\section{Crosslinking of P2VP-b-PAMA and synthesis of P2VP-b- PAMA/APM hybrid material}

Crosslinking of P2VP-b-PAMA films and dispersing of the nanobrushes was conducted as published. ${ }^{[15]}$ Hybrid materials were synthesized by dropwise addition of $500 \mathrm{ml}$ of a dispersion of $200 \mathrm{mg}$ P2VP-b-PAMA in aqueous $\mathrm{HCl}(0.001 \mathrm{M})$ to a solution of $400 \mathrm{mg}$ of APM $\left(\left(\mathrm{NH}_{4}\right)_{6} \mathrm{Mo}_{7} \mathrm{O}_{24}\right)$ (Alfa Aesar) in $500 \mathrm{ml}$ aqueous $\mathrm{HCl}(0.001 \mathrm{M})$ under vigorous stirring. Separation and purification of the hybrid material was carried out as published. ${ }^{[15]}$

\section{Removal of P2VP-b-PAMA template and carburization}

The removal of PAMA core was carried out by calcination under vacuum $\left(10^{-3} \mathrm{mbar}\right)$ in a closed tube furnace at $320{ }^{\circ} \mathrm{C}$ (ramping rate $3{ }^{\circ} \mathrm{C} \mathrm{min}^{-1}$ ) for $2 \mathrm{~h}$. The resulting material was black. Carburization was accomplished by heating the calcined composite material in argon atmosphere to $700{ }^{\circ} \mathrm{C}$ (ramping rate $3{ }^{\circ} \mathrm{C} \mathrm{min}^{-1}$ ) for $2 \mathrm{~h}$.

\section{Characterization}

SAXS data were measured using the small-angle X-ray system "Double Ganesha AIR" (SAXSLAB, Denmark). The X-ray source of this laboratory-based system is a rotating anode (copper, MicoMax 007HF, Rigaku Corporation, Japan) providing a microfocused beam. The data are recorded by a position sensitive detector (PILATUS 300K, Dectris). The circularly averaged data were normalized to incident beam, sample thickness and measurement time. To fit the scattering data the program Scatter was used. ${ }^{[13]}$ XRD (X-ray diffraction) patterns were recorded using a PANalytical X'pert Pro diffractometer fitted with a solid state $\mathrm{X}^{\prime}$ Celerator detector. The diffractometer was operated with $\mathrm{Cu} \mathrm{K \alpha}$ radiation $(1.541874 \AA, 40 \mathrm{kV}, 40 \mathrm{~mA})$ in reflection mode. $\mathrm{N}_{2}$ physisorption measurements were carried out on a Quantachrome Autosorb 1. Prior to the measurements the samples were degassed under high vacuum at $120{ }^{\circ} \mathrm{C}$ for $24 \mathrm{~h}$. Specific surface area was calculated using the five-point BET (Brunauer-Emmett-Teller) equation. SEM (scanning electron microscopy) was performed on a Zeiss LEO1530 FESEM. TEM (transmission electron microscopy) and HRTEM measurements were conducted on a FEI TITAN operating at $300 \mathrm{kV}$. The samples were placed on lacey carbon coated copper grids. TG-MS (thermogravimetric analysis coupled with mass spectroscopy) was performed on a Netzsch STA 449 from $25{ }^{\circ} \mathrm{C}$ to $1000{ }^{\circ} \mathrm{C}$ in helium atmosphere. The chemical composition of the materials was determined by elemental analysis. The contents of $\mathrm{H}, \mathrm{N}$, and $\mathrm{O}$ were quantitatively determined by carrier-gas hot-extraction technique (TCH 600, LECO) and the content of $\mathrm{C}$ by a combustion technique (C200, LECO). The analytical results derive from three independent measurements each of 5-7 mg of a grained sample. The catalytic activity was tested in a fixed-bed reactor equipped with a quartz tube $(6 \mathrm{~mm}$ 
diameter) fitted with a porous quartz frit. The reactor was loaded with about $25( \pm 1) \mathrm{mg}$ of the catalyst. For testing the catalytic activity, the reactor was fed with pure ammonia (BOC grade $3.8 \mathrm{~N}$, $\mathrm{SV} 15000 \mathrm{ml} \mathrm{g}_{\text {catalyst }}{ }^{-1} \mathrm{~h}^{-1}$ ). In a typical $\mathrm{NH}_{3}$ conversion experiment, the reactor temperature was raised from $300{ }^{\circ} \mathrm{C}$ to $700{ }^{\circ} \mathrm{C}$ with heating steps of $50{ }^{\circ} \mathrm{C}\left(16.7{ }^{\circ} \mathrm{C} \mathrm{min}{ }^{-1}\right)$. At each temperature step, the reaction equilibrated for 30 minutes; within the 30 minutes, four data points were recorded under steady-state conditions. Reaction products were analyzed using a Agilent 3000 Micro Gas Chromatograph (MolSieve $5 \AA$ and PLOT U columns and TCD detector, $\mathrm{H}_{2}$ and $\mathrm{Ar}$ as carrier gases).

Supporting Information (see footnote on the first page of this article): SAXS measurement of crosslinked P2VP-b-PAMA film, TEM images of dispersed P2VP- $b$-PAMA nanowires, TG-MS measurement of P2VP- $b$-PAMA/APM hybrid material, HRTEM and SAED of molybdenum carbide nanotubes, detailed synthesis and characterization of P2VP-b-PAMA diblock copolymer.

\section{Acknowledgement}

The authors wish to thank Professor R. Schlögl (Fritz-Haber Institute, Berlin) for access to HRTEM, Professor S. Förster (University of Bayreuth) for access to SAXS, Prof. F. Schüth (Max Planck Institute, Mülheim) for catalytic tests, Prof. A. Greiner (University of Bayreuth) for supply with polymers, Bianca Uch (MCII, University of Bayreuth) for GPC measurements and Professor C. Felser (MPI CPfS, Dresden) for access to elemental analysis. This work was supported by the German Science Foundation (Grant SFB 840).

[1] a) N. Armaroli, V. Balzani, Angew.Chem., Int.Ed. 2007, 46 , 52-66; b) F. Schüth, R. Palkovits, R. Schlögl, D. S. Su, Energ.Environ.Sci. 2012, 5, 6278-6289; c) C. H. Christensen, T. Johannessen, R. Z. Sorensen, J. K. Norskov, Catal.Today 2006, 111, 140-144.

[2] a) A. Amano, H. Taylor, J.Am.Chem.Soc. 1954, 76, 42014204; b) F. Hayashi, Y. Toda, Y. Kanie, M. Kitano, Y. Inoue, T. Yokoyama, M. Hara, H. Hosono, Chem.Sci. 2013, 4, 3124-3130.

[3] a) R. B. Levy, M. Boudart, Science 1973, 181, 547-549; b) A. M. Alexander, J. S. J. Hargreaves, Chem.Soc.Rev. 2010, 39, 4388-4401.

[4] A. Hanif, T. C. Xiao, A. P. E. York, J. Sloan, M. L. H. Green, Chem.Mater. 2002, 14, 1009-1015.

[5] a) J. S. Lee, S. T. Oyama, M. Boudart, J.Catal. 1987, 106 , 125-133; b) J. S. Lee, L. Volpe, F. H. Ribeiro, M. Boudart, J.Catal. 1988, 112, 44-53.

[6] C. M. A. Parlett, K. Wilson, A. F. Lee, Chem.Soc.Rev. 2013, 42, 3876-3893.

[7] T. Lunkenbein, D. Rosenthal, T. Otremba, F. Girgsdies, Z. H. Li, H. Sai, C. Bojer, G. Auffermann, U. Wiesner, J. Breu, Angew.Chem., Int.Ed. 2012, 51, 12892-12896.

[8] T. Lunkenbein, M. Kamperman, M. Schieder, S. With, Z. H. Li, H. Sai, S. Förster, U. Wiesner, J. Breu, J.Mater.Chem.A 2013, 1, 6238-6248.

[9] C. M. Yang, B. Zibrowius, W. Schmidt, F. Schüth, Chem.Mater. 2004, 16, 2918-2925.

[10] M. Schieder, T. Lunkenbein, T. Martin, W. Milius, G. Auffermann, J. Breu, J.Mater.Chem.A 2013, 1, 381-387.

[11] S. Zulfiqar, A. Piracha, K. Masud, Polym.Degrad.Stabil. 1996, 52, 89-93.
[12] A. Elmaci, J. Hacaloglu, Polym.Degrad.Stabil. 2009, 94, 738-743.

[13] a) S. Förster, L. Apostol, W. Bras, J.Appl.Cryst. 2010, 43, 639-646; b) S. Förster, S. Fischer, K. Zielske, C. Schellbach, M. Sztucki, P. Lindner, J. Perlich, Adv.Colloid Interface Sci. 2011, 163, 53-83.

[14] W. Zheng, T. P. Cotter, P. Kaghazchi, T. Jacob, B. Frank, K. Schlichte, W. Zhang, D. S. Su, F. Schüth, R. Schlögl, J. Am. Chem. Soc. 2013, 135, 3458-3464.

Received: ((will be filled in by the editorial staff)) Published online: ((will be filled in by the editorial staff)) 


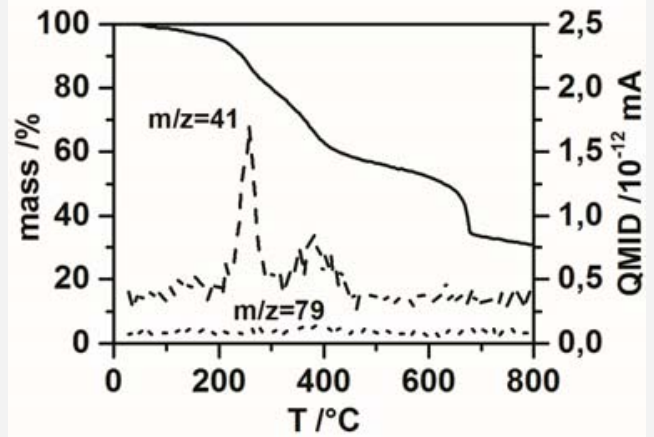

Martin Schieder, Thomas Lunkenbein, Carina Bojer, Martin Dulle, Julia vom Stein, Gudrun Auffermann, Tina Löbling, Judith Schöbel, Holger Schmalz, Josef Breu* ........ Page No. - Page No.

Selective template removal by thermal depolymerization to obtain mesostructured molybdenum oxycarbide 